\title{
Sexualidade das Pessoas com Deficiência Física: uma Análise à Luz da TeOria das RepresentaÇóEs Sociais ${ }^{1,2}$ \\ SeXuality of PeOple With Physical Disabilities: Na Analysis in the Light of THE THEORY OF SOCIAL REPRESENTATIONS
}

\author{
Alana Nagai Lins de CARVALHO 3 \\ Joilson Pereira da SILVA ${ }^{4}$
}

\begin{abstract}
RESUMO: Este artigo buscou responder ao seguinte questionamento: Como as pessoas transversalizam a questão do corpo nos discursos sobre a sexualidade das pessoas com deficiência e, assim, na elaboraçáo de suas representaçóes sociais? O objetivo principal foi discutir a sexualidade das pessoas com deficiência à luz da Teoria das Representaçóes Sociais (TRS), utilizando fotografias, como técnica, para a identificação dessas representaçôes. A pesquisa contou com a participação voluntária de 20 estudantes universitários (10 sem deficiência e 10 com deficiência física), de cursos das Ciências Humanas e Sociais, de uma universidade pública, distribuídos igualmente entre ambos os sexos (10 homens e 10 mulheres), com idades entre 19 e 59 anos, recrutados a partir de uma amostragem não probabilística (por conveniência) e da técnica snowball. Os dados foram obtidos a partir do questionário sociodemográfico, para a caracterizaçâo do perfil dos participantes, e da entrevista semiestruturada, na qual um dos questionamentos utilizou a foto-linguagem, que será o foco de análise deste artigo. Os dados produzidos na pesquisa foram analisados a partir do software IRAMUTEQ, ao utilizar a Classificação Hierárquica Descendente (CHD) e os dados quantitativos, pelo pacote estatístico SPSS, com o uso da estatística descritiva. Os resultados foram divididos em corpus, um referente às respostas das pessoas com deficiência física (Experiências de sexualidade na deficiência) e outro com as pessoas sem deficiência (Percepções sobre a sexualidade na deficiência). As representaçôes sociais encontradas foram distribuídas nas seguintes temáticas: vida com deficiência e limitações; corpo com deficiência e autoimagem; relação sexual; casamento; reprodução; família.
\end{abstract}

PALAVRAS-CHAVE: Representação social. Sexualidade. Pessoa com deficiência. Fotografia. Educação Especial.

\begin{abstract}
This article sought to answer the following question: How do people cross-refer to the issue of the body, in the discourses on the sexuality of people with disabilities, and, thus, in the elaboration of their social representations? The main objective was to discuss the sexuality of people with disabilities in the light of the Theory of Social Representations (TRS), using photographs as a technique to identify these representations. The research involved the voluntary participation of 20 university students (10 without disabilities and 10 with physical disabilities) enrolled in Human and Social Sciences courses, from a public university, distributed equally between both sexes ( 10 men and 10 women), with ages between 19 and 59 years, recruited from a non-probabilistic sampling (for convenience) and the snowball technique. The data were obtained from the sociodemographic questionnaire, to characterize the profile of the participants, and from the semi-structured interview, in which one of the questions used the photo-language, which will be the focus of analysis of this article. The data produced in the research were analyzed through the software IRAMUTEQ, from the Descending Hierarchical Classification (CHD) and the quantitative data, using the SPSS statistical package, with descriptive statistics. The results were divided into corpus, one referring to the responses of people with physical disabilities (Experiences of sexuality in disabilities) and the other with people without disabilities (Perceptions about sexuality in disabilities). The social representations found were distributed in the following themes: life with disabilities and limitations; body with disability and self-image; sexual intercourse; marriage; reproduction; family.
\end{abstract}

KEYWORDS: Social representation. Sexuality. Person with disability. Photography. Special Education.

\footnotetext{
${ }^{1}$ https://doi.org/10.1590/1980-54702021v27e0198

${ }^{2}$ Este trabalho foi realizado com o apoio da Coordenação de Aperfeiçoamento de Pessoal de Nível Superior - Brasil (CAPES) Código de Financiamento 001.

${ }^{3}$ Pesquisadora autônoma. Mestra em Psicologia pela Universidade Federal de Sergipe (UFS). São Cristóvão/Sergipe/Brasil. E-mail: Alana_adustina@hotmail.com. ORCID: https://orcid.org/0000-0002-8676-5682

${ }^{4}$ Doutor em Psicologia pela Universidad Complutense de Madrid (UCM) - Espanha. Pós-doutor em Psicologia pela Universitat Autònoma de Barcelona (UAB) - Espanha. Mestre em Psicologia pela Universidade Federal da Paraíba (UFPB). Graduado em Psicologia pela UFPB. Graduado em Estudos Sociais e Geografia pela Universidade Estadual da Paraíba (UEPB). Professor Associado da Universidade Federal de Sergipe (UFS) e professor credenciado do Programa de Pós-Graduação em Psicologia (PPGPSI). São Cristóvão/Sergipe/Brasil. E-mail: joilsonp@hotmail.com. ORCID: https://orcid.org/0000-0001-9149-3020
} 


\section{INTRODUÇÁo}

A Teoria das Representações Sociais (TRS) está vinculada às ciências sociais, especificamente à Psicologia Social. Ela surge com os estudos de Serge Moscovici, o qual buscava superar o caráter individualista da Psicologia, ao agregar a ela explicaçóes sociais. Assim sendo, o conceito de representaçóes sociais está relacionado a uma forma de conhecimento sobre algo ou alguém, construída e partilhada socialmente, a qual orienta as compreensóes e explicaçóes sobre os elementos sociais - coisas, pessoas e conhecimentos, por exemplo (Costa \& Almeida, 1999).

A sexualidade, em suas diferentes dimensões, é um exemplo de objeto de estudo para a TRS, afinal, cada sujeito possui diferentes conceitos, explicaçóes e crenças, baseados em seu conhecimento construído, os quais orientam suas açóes e seu entendimento sobre o assunto e podem se assemelhar ou se diferenciar, de acordo com o grupo social do qual participa e com o qual constrói e reconstrói suas representaçóes.

Segundo o modelo social, a deficiência caracteriza-se como uma experiência que envolve o sujeito e a estrutura social, a qual se manifesta quando esse sujeito vivencia situaçóes de opressão devido à sua condição de deficiência, ou seja, pelo corpo deficiente - Decreto $n^{\circ}$ 6.949, de 15 de agosto de 2009 - (Diniz, 2007; Maia, 2011). Logo, o estudo sobre a sexualidade das pessoas com deficiência adentra-se nas questóes referentes ao corpo.

O corpo pode ser apresentado a partir de diferentes perspectivas: para a religião, é desvalorizado no Cristianismo e preservado pelos protestantes; na filosofia, foi considerado em sua visão global (Sócrates), foi dicotomizado (Platão) ou integralizado (Aristóteles); a antropologia considera a influência da cultura em sua formação e modificação; biologicamente, está relacionado à sua anatomia e fisiologia; já psicologicamente, está vinculado ao bem-estar expresso nas sensaçóes. Enfim, trata-se de um conceito social, histórico, cultural, biológico e psicológico (Triani et al., 2015).

Atualmente, o que se entende por corpo é uma ideia construída com base no que se apreende do meio, por intermédio das relaçóes, das percepções e das experiências, e, assim, caracteriza-se como um objeto de representaçóes sociais. Os discursos da sociedade contemporânea apresentam um culto ao corpo, à estética e aos padróes de beleza, como uma mercadoria de consumo (Goldenberg \& Ramos, 2007). Diante disso, as representaçóes sociais sobre esse corpo sofrem influência dessas questóes.

Em uma pesquisa documental, Goetz et al. (2008) investigaram como a mídia impressa, em revistas de circulação nacional, apresenta as representaçóes sociais sobre o corpo. $\mathrm{O}$ material encontrado foi dividido em duas temáticas (beleza e saúde), por meio das quais foram constatados dois aspectos de representação do corpo: físico, com maior predomínio entre os achados, relacionado ao embelezamento e à saúde do organismo; e físico-psíquico, relativo à importância do equilíbrio e do bem-estar.

De forma mais pontual, Justo e Camargo (2013) investigaram, a partir de uma revisão de literatura, como o corpo é entendido na Psicologia Social e especificamente na TRS. Os autores consideraram o corpo em suas dimensôes tanto individual quanto social, sendo essa última o resultado das construçóes sociais, ao destacar-se nos trabalhos científicos e na mídia e ao repercutir nas relaçóes com o próprio corpo e com o corpo do outro. Então, constatou- 
-se que a TRS permite uma compreensão mais geral desse objeto ao estudar suas dimensôes de forma integralizada, uma vez que possibilita o entendimento do processo de formação das representações sociais sobre ele.

Os achados empíricos corroboram os dados apresentados anteriormente e confirmam como os diferentes meios de comunicação contribuem para a formação das representações sociais. Por exemplo, Camargo et al. (2010) estudaram os comportamentos e o pensamento social relacionados ao corpo, a partir da TRS, e encontraram uma maior insatisfação corporal e maior aderência às normas sociais e às práticas corporais entre as mulheres e os mais jovens. De um modo geral, a maioria dos participantes apresentou um Índice de Massa Corporal (IMC) saudável, mas era insatisfeita com o corpo, não praticava atividades físicas e optava por dietas restritivas ou cirurgias plásticas, em menor proporção. As normas sociais correspondiam à importância dada ao controle de peso, ao olhar do outro e à comparação com ele. A aparência foi citada como o que chama atenção no outro, mas, no momento de conhecê-lo, as características subjetivas foram consideradas mais importantes.

Camargo et al. (2011), em um estudo sobre as práticas corporais e representaçóes sociais de estudantes universitários sobre o corpo, constataram o que foi denominado como “culto à beleza corporal”, com predomínio de práticas de embelezamento em comparação ao cuidado com a saúde. Passos et al. (2013) encontraram dados semelhantes ao pesquisarem as representaçóes sociais de estudantes adolescentes sobre o corpo. Enquanto a saúde foi relacionada exclusivamente ao sentir-se bem com o corpo apresentado, a beleza apareceu construída com base nos padróes estéticos da mídia, os quais causam uma preocupação constante com a aparência, ao fazer do corpo um objeto de consumo e uma forma de atingir o prestígio.

Ao considerar o que foi apresentado, este artigo busca entender: Como as pessoas transversalizam a questão do corpo nos discursos sobre a sexualidade das pessoas com deficiência e, assim, na elaboração de suas representações sociais? Tem-se como objetivo principal discutir a sexualidade das pessoas com deficiência à luz da Teoria das Representaçóes Sociais, utilizando fotografias, como técnica, para a identificação dessas representações.

\section{Método}

Nesta seção, trata-se do perfil dos participantes da pesquisa, dos instrumentos e dos procedimentos escolhidos para a coleta de dados e da sua análise.

\subsection{Participantes}

Esta pesquisa de campo, com metodologia qualitativa e delineamento descritivo, contou com a participação voluntária de 20 estudantes dos cursos de Ciências Humanas e Sociais, de uma universidade pública, distribuídos igualmente entre ambos os sexos (10 homens e 10 mulheres), com idades entre 19 e 59 anos, recrutados a partir de uma amostragem não probabilística (por conveniência) e da técnica snowball.

Dentre essa amostra, estavam 10 universitários com deficiência física e 10 sem deficiência. Foram escolhidos universitários das Ciências Humanas e Sociais, a fim de conhecer a compreensão e a representação desses sujeitos, futuros profissionais, sobre a temática estudada. 


\subsection{INSTRUMENTOS E PROCEDIMENTOS}

Além do questionário sociodemográfico, usado para caracterizar o perfil dos participantes, a entrevista semiestruturada também foi aplicada, na qual um dos questionamentos utilizados foi a foto-linguagem (Brito et al., 2015), que será o foco de análise deste artigo.

O uso de fotografias é um importante recurso de estímulo para a comunicação e a manifestação da subjetividade, com vistas a produzir sentido e significado a partir das falas, percepçóes e reaçóes das pessoas sobre as fotos (Neiva-Silva \& Koller, 2002). A foto-linguagem é um estímulo indutor, em que, a partir da apresentação de imagens, apreende-se a compreensão dos sujeitos sobre a temática proposta (Brito et al., 2015). Desse modo, não se trata de um estudo sobre as fotografias, mas como uma forma de representação sobre a temática proposta, para auxiliar a produção de material textual, a partir da expressão de sua significação (Justo \& Vasconcelos, 2009).

Inicialmente, a indicação dos participantes foi feita por outros estudantes da instituição. A partir do contato, foram esclarecidas as informaçóes sobre o estudo e realizado o convite para a composição da amostra da pesquisa, que foi conduzida pela primeira autora deste artigo, nas dependências da instituição, de forma individual, nos dias e horários acordados. Foi utilizado o Termo de Consentimento Livre e Esclarecido (TCLE) que, além de apresentar a pesquisa, autorizava a gravação, em áudio, das entrevistas, e permitia a posterior transcrição dos dados e maior fidedignidade às falas na análise. A cada entrevista, potenciais participantes eram indicados.

A foto-linguagem foi aplicada da seguinte maneira: quatro fotografias de domínio público representavam pessoas com diferentes tipos de deficiência, exercendo sua sexualidade, seus direitos sexuais e reprodutivos (se casadas, com filhos, posando nuas, por exemplo), impressas separadamente em folhas de ofício A4. Elas foram apresentadas durante 30 segundos cada, com a orientação: "A seguir, serão apresentadas algumas imagens. Gostaria que você as olhasse atentamente e escolhesse uma que foi mais significativa para você”. Após a apresentação e escolha, o participante descrevia a fotografia escolhida e relatava o porquê da escolha.

Com relação às fotografias utilizadas, a primeira apresentava uma mulher com deficiência visual em um ensaio sensual; a segunda continha uma família, com uma criança no colo, na qual os pais eram cegos; a terceira fotografia correspondia a um homem com deficiência física, posando sensualmente; já a quarta, representava uma família, com dois filhos, em que ambos os cônjuges possuíam deficiência física.

O processo de seleção das fotografas foi desenvolvido pela pesquisadora, primeira autora deste artigo, e avaliado por quatro juízes, que escolheram entre oito imagens, previamente selecionadas, quatro que melhor representavam e eliciavam o conteúdo pesquisado. Por essa razão, nem todos os tipos de deficiências foram retratados nas imagens, assim como não foram representadas diferenças étnicas e de configurações familiares, por exemplo.

Conforme a Resolução no 510, de 7 de abril de 2016, do Conselho Nacional de Saúde (CNS), sobre pesquisas com seres humanos, este estudo possui Certificado de Apresentação para Apreciação Ética (CAAE) 81030617.9.0000.5546 e Parecer de aprovação n ${ }^{\circ}$ 2.514.67, emitidos pelo Comitê de Ética em Pesquisa (CEP) envolvendo Seres Humanos da Universidade Federal de Sergipe. 


\subsection{ANÁLISE DE DADOS}

Os dados produzidos na pesquisa foram analisados a partir do software IRAMUTEQ (Interface de R pour les Analyses Multidimensionnelles de Textes et de Questionnaire) versão 0.7, a partir da Classificação Hierárquica Descendente (CHD). Os dados obtidos com o questionário sociodemográfico foram submetidos à estatística descritiva, a partir do Statistical Package for the Social Sciences (SPSS), versão 22.

\section{Resultados E Discussão}

A caracterização do perfil dos participantes e a fotografia escolhida por cada um deles estão expostas na Tabela 1, que utilizou nomes fictícios para garantir o anonimato dos participantes.

\section{Tabela 1}

Caracterizaçâo do perfil dos participantes e escolha da fotografia

\begin{tabular}{|c|c|c|c|c|c|c|c|c|c|c|c|}
\hline \multicolumn{6}{|c|}{ Pessoas com Deficiência física } & \multicolumn{6}{|c|}{ Pessoas sem Deficiência } \\
\hline Nome & I & $\mathbf{F}$ & Nome & I & $\mathbf{F}$ & Nome & I & $\mathbf{F}$ & Nome & I & $\mathrm{F}$ \\
\hline Alice & 38 & 4 & Guilherme & 52 & 2 & Amanda & 25 & 2 & Letícia & 28 & 2 \\
\hline Arthur & 23 & 2 & Jorge & 59 & 2 & Bernardo & 19 & 1 & Mariana & 25 & 2 \\
\hline Beatriz & 42 & 3 & Laura & 27 & 4 & Camila & 26 & 4 & Matheus & 43 & 2 \\
\hline Eduarda & 24 & 4 & Rafael & 21 & 2 & Gustavo & 19 & 3 & Pedro & 19 & 3 \\
\hline Gabriel & 26 & 3 & Sofia & 30 & 4 & Larissa & 23 & 4 & Raul & 21 & 1 \\
\hline
\end{tabular}

Nota. I (Idade); F (Foto escolhida).

A partir dos dados da Tabela 1, a média de idade dos participantes é de 29,5 anos (Desvio Padrão-DP = 11,358). As mulheres apresentam a média de 28,8 e os homens de 30,2. No que se refere à fotografia, estas foram as escolhas dos participantes: foto $1(n=2) ; 2(n=8)$; $3(n=4)$; e $4(n=6)$.

Entre as pessoas com deficiência física, a média de idade é de 34,2 anos (DP = 13,113); 32,2, a média feminina; e 36,2, a masculina. A escolha da fotografia concentrou-se nas fotos 2 $(n=4), 3(n=2)$ e $4(n=4)$. Com relação ao grupo de participantes sem deficiência, a média de idade é de 24,8 anos (DP $=7,162$ ), com média feminina de 25,4 e masculina de 24,2 . A escolha das fotos foi dividia da seguinte maneira: foto $1(n=2) ; 2(n=4) ; 3(n=2) ; 4(n=2)$.

Com relação às falas decorrentes da foto-linguagem, os dados produziram dois corpo$r a$ : um referente às respostas das pessoas com deficiência física (Experiências de sexualidade na deficiência) e outro com as pessoas sem deficiência (Percepçóes sobre a sexualidade na deficiência). Esses corpora foram analisados pelo software IRAMUTEQ a partir da CHD, que classifica os segmentos do texto (ST) de acordo com as semelhanças e as diferenças entre os vocábulos, reunindo-os ou repartindo-os, respectivamente (Camargo \& Justo, 2013). 
Os resultados e as discussóes de cada corpus e as suas respectivas classes estão expostos a seguir, juntamente às figuras (dendograma) que ilustram o processo de divisão, o nome das classes, a quantidade e a porcentagem dos segmentos de texto que as compóem, bem como a frequência $(\mathrm{F})$ das palavras associadas $\left(\mathrm{x}^{2}\right)$.

\subsection{EXPERIÊNCIAS DE SEXUALIDADE NA DEFICIÊNCIA}

O corpus é composto por 10 textos, referentes às falas das pessoas com deficiência física, no qual foram identificados 86 ST, 659 palavras, com 2.899 ocorrências, e uma média de aproximadamente 4,39 vezes por palavra. A CHD considerou 68 ST (79,07\%) para a análise. A divisão do corpus foi feita em quatro classes. Inicialmente, foram gerados dois subcorpus, com as Classes 4 e 3 opondo-se às demais; a seguir, as Classes 4 e 3 foram separadas e, finalmente, as Classes 1 e 2 sofreram uma partição (Figura 1).

\section{Figura 1}

Dendograma da Classificação Hierárquica Descendente (CHD) do corpus "Experiências de sexualidade na deficiência"

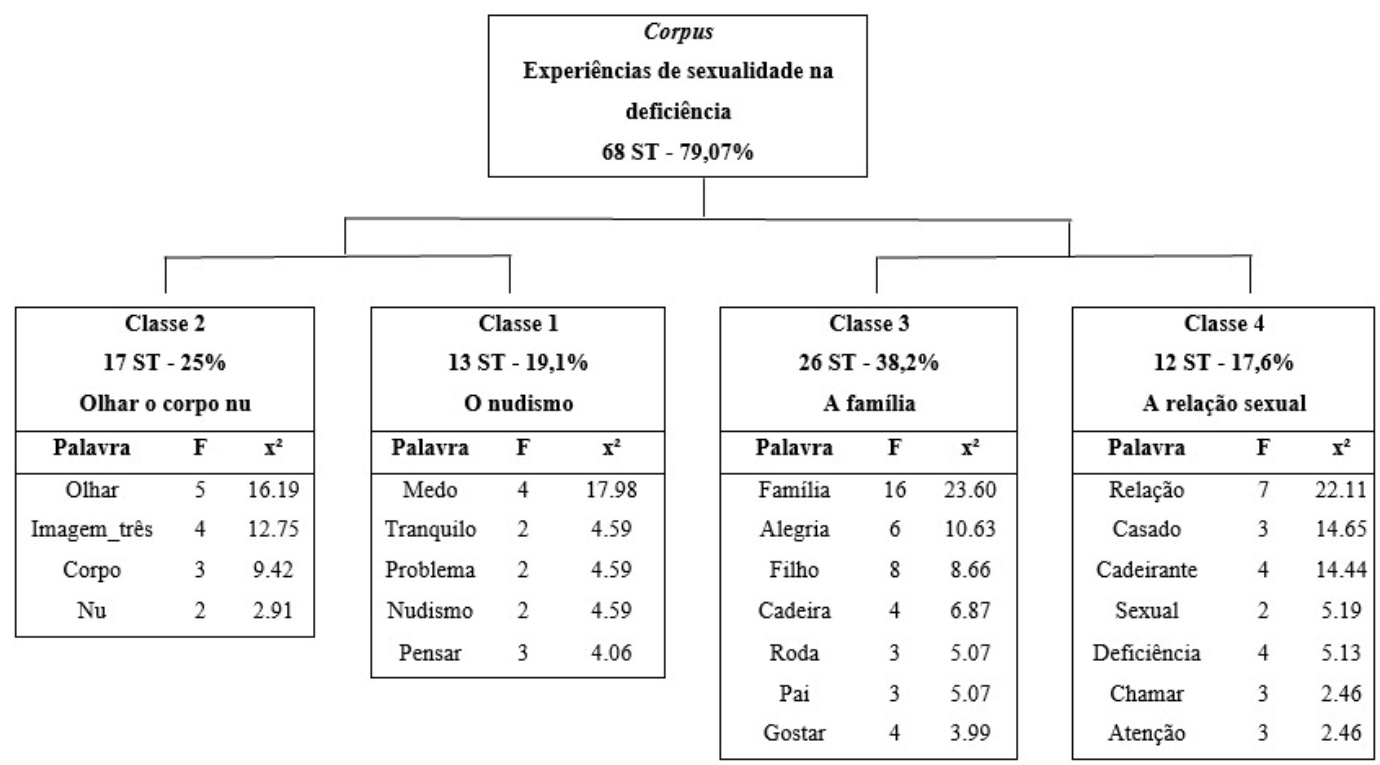

A primeira classe a se diferenciar nesse corpus (Classe 4), denominada "A relação sexual", possui a menor quantidade de ST, 12 (17,6\%) e reúne as falas de Alice e Eduarda sobre a Fotografia 4, que foi descrita pelos termos "cadeirante", "deficiência" e "casado". As participantes trouxeram relatos diante do que chamou ("chamar") "atenção" na foto, ao associar as experiências pessoais de "relação" "sexual", como é possível perceber no extrato a seguir:

O que me chamou atençáo foi a questão de eles serem família, provavelmente casados e os dois serem cadeirantes. Como eu sou cadeirante e eu tive relação com um cadeirante, eu percebi... um certo preconceito das pessoas com deficiência terem relação com pessoas com deficiência. (Eduarda) 
Esse extrato mostra, a princípio, a representação da Fotografia 4, a qual está relacionada à formação familiar que, posteriormente, é associada às vivências sexuais da participante, uma vez que mostra a relação sexual como parte das experiências de sexualidade das pessoas com deficiência física. Esse fato corrobora a investigação de Chappell (2014) sobre as falas de pessoas com deficiência física e visual acerca do amor, das relaçóes, do sexo, do HIV, da AIDS e sobre as suas implicações na construção da identidade sexual, pois constata que a deficiência não se caracteriza como uma condição limitadora das experiências sexuais.

Ao final de sua fala, Eduarda refere-se ao preconceito social que se manifesta quando as pessoas com deficiência vivenciam sua sexualidade. Nesse sentido ela ancora o seu conhecimento sobre a temática às atitudes sociais vivenciadas quando se apresentou socialmente em um relacionamento com uma pessoa que também possuía deficiência, e denomina tais atitudes como formas de preconceito.

A ancoragem é um processo gerador das representaçóes sociais, na qual uma ideia estranha ou problemática é categorizada ao que nos é familiar, conhecido (Moscovici, 2010). Dessa maneira, o preconceito social relatado pela participante surge como uma forma de ancoragem. Além disso, trata-se de uma legitimação do corpo com deficiência (Jones et al., 2015), ao associar-lhe estereótipos, estigmatizando-o, e ao impedir o desenvolvimento sexual saudável e gratificante (Damas et al., 2015).

"A família” é destaque na Classe 3, que possui a maior quantidade de ST, 26 ao todo, e representa uma parcela de 38,2\% do total, construída com as falas de Laura, Sofia, Arthur e Rafael sobre as Fotografias 2 e 4 . O foco principal foi a representação de "família", com "pai" e "filho", e as características da Fotografia 4, ao citar a "cadeira" de "roda". As escolhas foram feitas pelo "gostar", ancoradas às emoçóes e aos comportamentos de "alegria".

Eu gostei dessa (2), que é um casal de cegos segurando uma bebezinha e deve ser a filha deles e eu gostei dela justamente por, aí velho, tá percebendo o sorriso do pai, a alegria dele? Ele tá sentindo a nenenzinha nos braços, então foi a que eu mais gostei porque eu achei bem emocionante. (Arthur)

Diferentemente da classe anterior, a fala de Arthur concentra-se somente na relação entre as pessoas com deficiência e na construção familiar, em outras palavras, no exercício da conjugalidade e da parentalidade. No entanto, ao descrever a imagem, o participante ancora o que está sendo ilustrado com emoçóes e comportamentos, como o sorriso, a alegria e a emoção.

A conjugalidade e a parentalidade são formas de exercício dos direitos sexuais e reprodutivos. Pesquisas como a de Bloom et al. (2017) mostram que o desejo e a intenção de fertilidade entre as mulheres com e sem deficiência são semelhantes. Outros estudos como os de Gartrell et al. (2017), Pérez (2015) e Tanabe et al. (2015) identificaram, porém, falhas no acesso aos serviços de saúde sexual e reprodutiva por pessoas com deficiência, como, por exemplo, a falta de acessibilidade, as práticas tradicionais e discriminatórias, além da falta de políticas e de programas governamentais.

Hunt et al. (2017) constataram, em seus achados, que as pessoas sem deficiência se consideravam como mais merecedoras dos direitos sexuais e reprodutivos e com mais benefícios nesses tipos de serviços, em comparação às pessoas com deficiência. Esses resultados levantam 
a problemática sobre a necessidade de que a sexualidade das pessoas com deficiência necessita de respeito em suas diferentes manifestaçóes e demandas para que, consequentemente, seus direitos sexuais e reprodutivos sejam efetivados.

A classe "O nudismo" (Classe 1), composta por 19,1\% dos ST (13), traz os conteúdos das entrevistas de Guilherme e Beatriz e dá maior destaque às falas desta última, em que são abordadas questôes referentes à Fotografia 3. A imagem é descrita pelo termo "nudismo", pois projeta as experiências pessoais da participante, as quais se caracterizam a partir da palavra "tranquilo" quanto à sua sexualidade; além disso, o "problema" seria o que o outro vai "pensar", as suas reaçôes; por isso, o vocábulo "medo" também se destacou na classe.

A questão do nudismo sempre me travou um pouco, antes de ter um namorado né, que eu achava que ninguém fosse se interessar [...] porque o meu medo, o problema não estava em mim, pra você ver, sempre preocupada com o que o outro vai pensar. Entáo, eu sempre fui uma pessoa tranquila, lia muito [...]. (Beatriz)

A sexualidade das pessoas com deficiência, representada na Fotografia 3, a partir do nudismo, é ancorada por Beatriz na ideia de corpo regido pelos padróes estéticos. Ademais, por mais que ela se sinta tranquila em relação à sua sexualidade, existe um problema em mostrar o seu corpo nu que repercute no medo do que o outro vai pensar. Os estudos evidenciam as preocupaçóes da participante, pois o corpo é representado pela saúde e pela beleza, pelo físico e pela físico-psíquica (Goetz et al., 2008), como uma dimensão individual, mas também construído socialmente, evidenciado na mídia e nas produçóes científicas, tendo forte influência nas relaçóes que são estabelecidas de forma interpessoal ou intrapessoal com o corpo (Justo \& Camargo, 2013), ao destacar-se o culto à beleza, em detrimentos das práticas de cuidados com a saúde (Camargo et al., 2011; Passos et al., 2013).

No que concerne ao corpo com deficiência, o estudo de Agmon et al. (2016), apresenta-o como incapaz, dependente, infantil, assexuado e privado de diferentes funçóes, como o gênero. As questóes sobre a preocupaçáo com a imagem corporal, como algo que influencia na atratividade das pessoas com deficiência, e sobre o medo das reaçóes do parceiro foram também encontradas nas pesquisas de Abbott et al. (2015) e Jones et al. (2015), ao estudarem as problemáticas acerca da imagem corporal masculina e feminina, respectivamente.

Segundo Soares et al. (2008), as atitudes sociais e culturais negativas em relação ao corpo com deficiência repercutem em atitudes de recusa e medo da náo aceitação, semelhante ao que foi relatado por Beatriz. Destaca-se, aqui, a importância da desconstrução de padróes segregadores e estigmatizantes, tendo em conta a importância e a valorização da diversidade de corpos e das práticas sexuais.

Ainda falando sobre o corpo, a Classe 2, que corresponde a 17 ST, de 25\% do todo, intitulada "Olhar o corpo nu", traz as falas de Jorge e Gabriel que destacaram suas compreensões sobre as Fotografias 2 e 3. A "imagem_três", que teve maior destaque nas falas, foi interpretada a partir do "corpo" "nu" representado e do "olhar" do sujeito fotografado. A fala de Gabriel deixa claro essa descrição: "um cadeirante né, posando para uma foto nu (3), é uma afirmação pra mim, uma afirmação dele, da sexualidade dele... mas eu achei forte o olhar dele, é como se realmente ele, fosse uma afirmaçáo dele". 
Nesse extrato, a Fotografia 3 é representada pelo nudismo do outro, ou melhor, como Gabriel percebe o corpo nu com deficiência, pois descreve essa atitude como algo significativo, ancorada a um ato de afirmação de si e de sua sexualidade. Diferentemente da classe anterior, que ressalta o medo e a preocupação com os padróes estéticos, essa classe reforça a importância da diversidade, que se expressa, aqui, a partir da deficiência e das diferentes formas de vivência sexual a ela atreladas, uma vez que coloca em evidência a importância da valorização de si.

Segundo Dantas et al. (2014), esse processo pode ser denominado de empoderamento, que corresponde à tomada de consciência, de controle e de responsabilidade do sujeito sobre a sua vida, de acordo com os seus desejos e com o reconhecimento do seu valor. Esses autores constataram que as diferentes dimensões de vida, como, por exemplo, a família, a educação, o trabalho e a vida social em geral, contribuem para o processo de empoderamento e para o exercício da autoadvocacia, bem como influenciam no reconhecimento da identidade de gênero e de questóes sexuais em pessoas com deficiência.

\subsection{PercepÇóes Sobre a SeXualidade Na DeficiêNCIA}

Neste corpus, estão reunidos os discursos das pessoas sem deficiência, com o resultado de 10 textos, compostos por 62 ST e 540 palavras que ocorreram 2.034 vezes, o que deu uma média aproximada de 3,76 vezes por palavra. 50 ST $(80,65 \%)$ foram analisados na CHD. O processo de divisão desse corpus também resultou em quatro classes. $\mathrm{Na}$ primeira partição, a Classe 4 se opôs às demais; posteriormente, a Classe 1 foi separada e, por fim, as Classes 2 e 3 foram divididas (Figura 2). 


\section{Figura 2}

Dendograma da Classificação Hierárquica Descendente (CHD) do corpus "Percepçóes sobre sexualidade na deficiência"

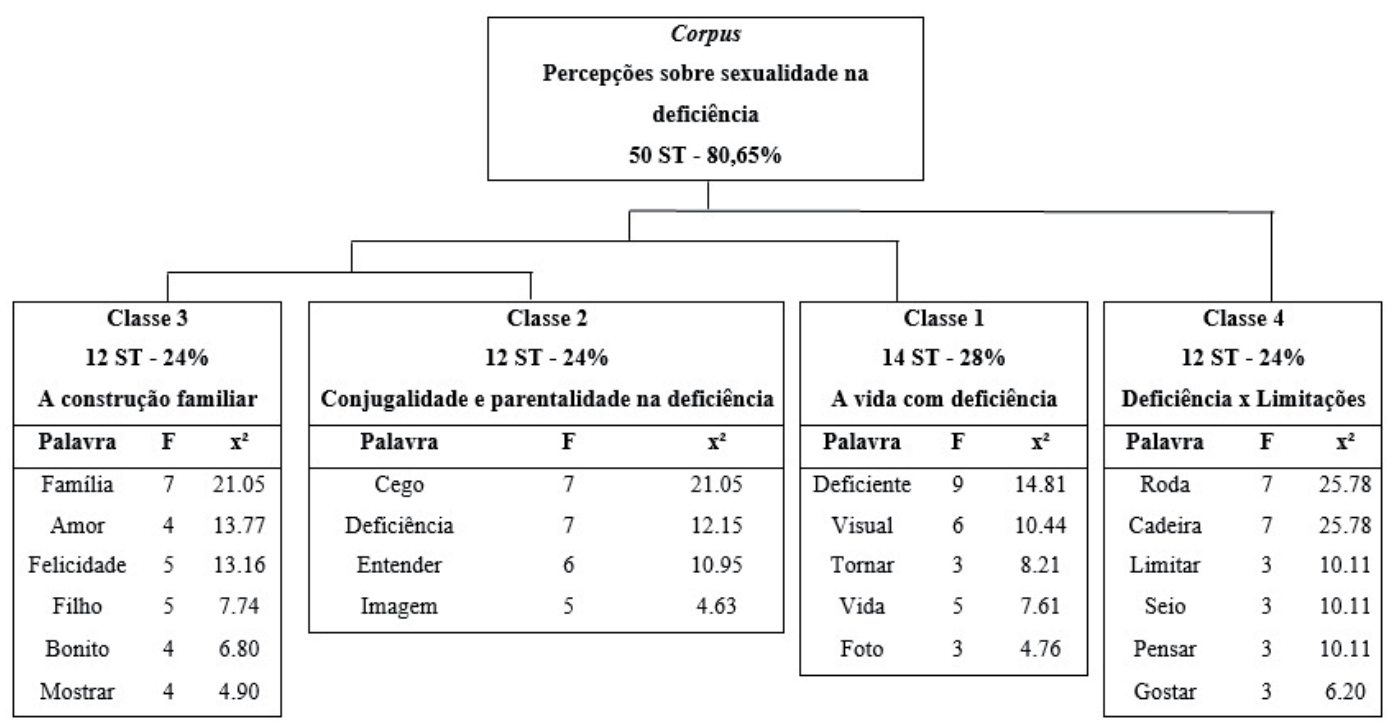

A primeira classe desse corpus (Classe 4), denominada "Deficiência x limitaçôes", é composta por 12 ST (24\%) e apresenta as falas de Pedro e Bernardo. As palavras "roda”, "cadeira" e "seio" destacaram-se por caracterizarem as Fotografias 3 e 1 escolhidas, respectivamente, pelos participantes. Além disso, os discursos revelaram que o "gostar" motivou a escolha das fotografias que, inicialmente, foram ancoradas à ideia de deficiência como limitação ("limitar"), mas que, posteriormente, oportunizaram o "pensar" sobre o assunto, o que objetivou uma nova situação, como é possível perceber no trecho que segue:

O rapaz da cadeira de rodas sozinho, é como se ele tivesse a mais a oferecer né, como se ele não se limitasse a cadeira de roda... por exemplo, se eu começasse a conversar com ele agora, ele teria uma conversa incrível sabe e eu nem ligasse pro fato dele tá numa cadeira de roda [...]. (Pedro)

As representaçóes apresentadas nessa classe demonstram que a imagem da pessoa com deficiência é ancorada na ideia de limitação; tais limitaçóes estariam relacionadas às representaçôes sobre a pessoa com deficiência como problemática, vulnerável, infantil, imatura e incapaz, por exemplo (Starke et al., 2016). Morgado et al. (2017) também encontram representaçôes sociais da deficiência relacionadas à limitação. Segundo esses pesquisadores, essa ancoragem está relacionada ao modelo médico de compreensão da deficiência, pois essas pessoas são vistas como pessoas doentes, que necessitam de cuidados médicos e que são as únicas responsáveis por suas condiçóes.

No decorrer da fala, o participante traça uma situação e abre espaço à possibilidade de conhecer a pessoa que existe além da deficiência, como alguém que tem mais a oferecer. Esse processo de transformação de algo abstrato, como uma descrição de uma imagem, em uma 
situação concreta ou quase concreta, ou seja, que pode ser palpável, chama-se objetivação, um dos processos geradores das representações sociais (Moscovici, 2010).

A pessoa com deficiência, que antes foi representada a partir da ideia de limitação, passa a ser vista como alguém com quem se pode ter uma conversa, por exemplo, e desconstrói-se o pensamento inicial. Algo semelhante foi encontrado na pesquisa de Marini et al. (2012), na qual os sujeitos que não tinham experiências anteriores com pessoas com deficiência eram menos propensos a relaçóes de amizade, namoro ou casamento; ao passo que os que já tinham contato anterior com pessoas com deficiência foram mais propensos aos diferentes tipos de relacionamentos citados.

A Classe 1, "A vida com deficiência", é a maior desse corpus, com $28 \%$ dos ST (14), e aborda as falas de Gustavo e Mariana sobre as Fotografias 2 e 3. O termo "deficiente" foi usado para se referir aos diferentes tipos de deficiências e, quando associado ao "visual", estava fazendo referência à "foto" 2. Os participantes também falaram sobre o se "tornar" deficiente e trouxeram suas percepçóes sobre a "vida" das pessoas com deficiência. A fala de Mariana caracteriza essa questão ao justificar o porquê da fotografia escolhida:

Porque eu acredito que eles venceram muitas barreiras para conquistar esse espaço e pra atingir esses objetivos na vida... por mais que a pessoa se torne um deficiente visual... pode sim se readaptar e aprender né, até porque quem é deficiente visual utiliza outros sentidos, como por exemplo a audição, a audiçáo se torna bem aguçada. (Mariana)

Nessa classe, as falas dos participantes trouxeram a representação sobre a pessoa com deficiência ainda ancorada ao modelo médico, pois, como apresentado no estudo de Morgado et al. (2017), essa representação responsabiliza o sujeito por sua condição; logo, ele também é o único responsável por superá-la. Aqui também surge o que Pereira et al. (2011) denominaram como uma representação de pessoas com deficiência ancorada à figura de herói. Trata-se de um estereótipo que considera esses indivíduos como "super-humanos" por enfrentarem as adversidades da vida, mas mascara as verdadeiras barreiras sociais, arquitetônicas e atitudinais do dia a dia.

Muitos estudos mostram que as pessoas com deficiência enfrentam barreiras adicionais em comparação às pessoas sem deficiência, como, por exemplo, para o exercício de seus direitos, como os sexuais e reprodutivos (Pérez, 2015), e acesso aos serviços de saúde sexual e reprodutiva (Gartrell et al., 2017; Tanabe et al., 2015).

Não se trata de individualizar a deficiência dos sujeitos e lançar mão da responsabilidade social, muito menos de mantê-los a partir de uma perspectiva assistencialista, mas, sim, de integrar essas propostas. Pesquisas como a de McKenzie (2013) mostram o posicionamento ativista das pessoas com deficiência na luta por conhecimento social, desenvolvimento e reconhecimento de seus direitos. É necessário que essas propostas recebam apoio e, principalmente, a participação social.

$\mathrm{Na}$ classe seguinte, "Conjugalidade e parentalidade na deficiência” (Classe 2), que representa 24\% dos ST (12), estão os extratos das entrevistas de Matheus, Letícia e Raul. A palavra "deficiência" foi usada para generalizar as diferentes deficiências, de modo especial a visual, representada na "imagem” 2, a qual também era caracterizada nas falas pelo vocábulo 
“cego". Além disso, o verbo "entender" se destacou como uma gíria, mas também com o sentido de compreensão, quando os participantes relatavam suas impressóes sobre as imagens, como é possível perceber na fala da Matheus:

Essa imagem, ela representa aqui um casal, aparentemente são cegos e com um bebê... não tem como afirmar se a criança é cega ou não, nem sempre isso acontece... é uma coisa muito difícil, assim geralmente, as pessoas, os cegos querem ter um relacionamento com uma pessoa que veja né, que não tenha essa deficiência. (Matheus)

Esse enunciado traz uma representação sobre a reprodução e o casamento entre as pessoas com deficiência. Especificamente sobre a reprodução, a fala do participante questiona a possibilidade de a criança na fotografia ter algum tipo de deficiência, ancorando-se nos mitos estudados por Maia e Ribeiro (2010) de que pessoas com deficiência geram filhos que também possuem deficiências. Entretanto, nesse estudo, os autores esclarecem que nem toda deficiência é hereditária.

Sobre o casamento, Matheus traz uma ideia de que pessoas com deficiência preferem casar-se com pessoas sem deficiência. Mais uma vez, há uma ancoragem com a ideia de limitação que seria superada, ou parcialmente superada, em um casamento, diferentemente do que foi constatado por Addlakha (2007) e Chappell (2014), no qual os participantes da pesquisa declararam que teriam relacionamentos tanto com pessoas com deficiência quanto com pessoas sem deficiência, pois não escolhem seus pretendentes pelo corpo, mas, sim, pela personalidade.

A última classe desse segundo corpus foi a Classe 3, "A construção familiar", que corresponde a 12 ST (24\%), em que aparecem as falas de Larissa, Camila e Amanda. As fotografias escolhidas foram a 2 e a 4, as quais representam a "família" e que foram vinculadas ao "amor". Outros termos, como "mostrar", reúnem descriçóes sobre as fotografias, nas quais são destacadas a figura do "filho", da "felicidade" e do "bonito".

Eu gostei muito dessa (2) e dessa (4), fiquei em dúvida porque as duas são bonitas, mostrando assim a família... apesar da deficiência né, tem dois filhos, que eu acho que são deles né, que tá na foto, é uma família feliz, me motivou por, pela, assim pela felicidade que demonstra na imagem... amor. (Larissa)

As Fotografias 2 e 4 reuniram representações sobre a família construída por pessoas com deficiência, as quais envolvem as duas temáticas trabalhadas na classe anterior, o casamento e a paternidade; mas, nessa classe, a fala da participante sugere uma dúvida quanto à paternidade representada na foto e uma surpresa com relação ao casamento, uma vez que surge uma ancoragem que questiona a execução dos direitos sexuais e reprodutivos pelas pessoas com deficiência.

Apesar das falas representarem um discurso de felicidade, beleza, gosto e amor, as pesquisas mostram que o desejo, a intenção e o exercício da maternidade pelas mulheres com deficiência e a construção de uma família foram foco de críticas e de rejeição, por parte de profissionais e de familiares (Jones et al., 2015; Pérez, 2015).

Diante dos dados expostos nessas duas últimas classes, percebe-se a necessidade do conhecimento social acerca da sexualidade das pessoas com deficiência, pois ainda é permeada 
por crenças, mitos, estereótipos e preconceitos. Não se trata apenas de construir leis, como as dos direitos sexuais e reprodutivos, mas é preciso que elas sejam amplamente difundidas, debatidas e efetivadas não só no âmbito jurídico, como também atitudinal, no dia a dia, nos discursos cotidianos.

\section{Conclusão}

Os corpora descritos anteriormente apresentam uma estreita relação, pois, apesar de serem construídos a partir de duas perspectivas distintas de uma mesma realidade, permitem reunir as representações das pessoas com deficiência física sobre a sexualidade das pessoas com deficiência, emitidas a partir das Fotografias 2, 3 e 4, direcionadas às experiências pessoais, e de pessoas sem deficiência, com base nas Fotografias 1, 2, 3 e 4, relacionadas às percepçóes sobre essa sexualidade que lhes é alheia. Essas representações estão reunidas nas seguintes temáticas: vida com deficiência e limitaçóes; corpo com deficiência e autoimagem; relação sexual; casamento; reprodução; família.

Os participantes utilizaram-se das fotografias para emitir as suas representaçóes sobre a sexualidade das pessoas com deficiência. Para as pessoas com deficiência física, essa sexualidade foi ancorada ao preconceito social, que vivenciam em experiências pessoais semelhantes, assim como às emoçóes despertadas pelas fotos e ao nudismo, na cobrança social referente aos padrôes estéticos de corpo ou como uma forma de afirmação.

Entre as pessoas sem deficiência, elas ancoraram, inicialmente, a deficiência à ideia de limitação, característica do modelo médico de compreensão da deficiência, e à ideia de heróis. Posteriormente, a sexualidade dessas pessoas foi ancorada no mito da hereditariedade da deficiência, no casamento como uma forma de superar as limitaçóes e no questionamento quanto ao exercício dos direitos sexuais e reprodutivos pelas pessoas com deficiência. Nesse último grupo, também foi possível identificar o processo de objetivação, quando, na fala de um dos participantes, a ideia de limitação é desconstruída a partir da construção de uma situação em que se pode conhecer mais sobre a pessoa com deficiência.

Ao traçar uma relação entre os resultados apresentados nos dois grupos, percebe-se que as Fotografias 2, 3 e 4 foram escolhidas por ambos. Entre as pessoas com deficiência física, a Fotografia 2 foi ancorada a emoçôes, como a alegria; já no outro grupo, a mesma fotografia foi ancorada aos mitos da hereditariedade da deficiência, do casamento como uma forma de superar as limitaçóes e à ideia de heróis. A terceira imagem foi ancorada, pelo primeiro grupo, aos padróes estéticos impostos ao corpo e à autoafirmação e, entre as pessoas sem deficiência, à ideia de limitação, objetivada na desconstrução dessa ideia, processo que também ocorreu com a Fotografia 1, que foi escolhida apenas nesse grupo. Com relação à Fotografia 4, esta foi ancorada pelas pessoas com deficiência física aos preconceitos sociais vivenciados e para os demais participantes ao questionamento sobre os direitos sexuais e reprodutivos na deficiência.

Os resultados apresentados salientam a necessidade de que a sexualidade das pessoas com deficiência ganhe maior destaque entre os discursos cotidianos. Os direitos sexuais e reprodutivos, que aparecem nas falas dos participantes e nas discussóes dos resultados, referem-se a leis que visam a garantir o livre exercício e a vivência da sexualidade, em todas as suas dimensões e de forma equitativa entre os sujeitos (Vasconcelos et al., 2017). 
Para que essas leis sejam devidamente efetivadas, faz-se necessário o conhecimento social sobre elas, e a produção científica é um dos caminhos, ao adentrar os centros acadêmicos e encontrar-se ao alcance dos profissionais que estão em formação e que levam o seu conhecimento para a comunidade. Além disso, essas leis podem também ser incluídas em grupos e palestras, para fomentar a discussão sobre a temática e visar a desconstruir estereótipos, estigmas e preconceitos e, também, valorizar a variedade de corpos e de práticas sexuais. Especificamente na área de Educação Especial, a pesquisa apresentada neste artigo contribui com o avanço no estado da arte, o que consequentemente implica o avanço de práticas profissionais voltadas às pessoas com deficiência, bem como ao empoderamento desses sujeitos.

As principais limitaçóes deste artigo estão relacionadas aos participantes: à quantidade de sujeitos, à escolaridade, à escolha dos recrutados em apenas uma instituiçáo e com apenas um tipo de deficiência. Ademais, também existem as limitaçóes metodológicas, relacionadas às fotografias utilizadas e à proposta exclusivamente qualitativa. Espera-se que esta pesquisa seja uma porta de possibilidades para outros estudos na temática, que possam vir a explorar outros métodos e a ampliar o número de participantes e os resultados aqui alcançados.

\section{REFERÊNCIAS}

Abbott, D., Jepson, M., \& Hastie, J. (2015). Men living with long-term conditions: exploring gender and improving social care. Health and Social Care in the Community, 24(4), 420-427. https://doi. org/10.1111/hsc. 12222

Addlakha, R. (2007). How young people with disabilities conceptualize the body, sex and marriage in urban India: Four case studies. Sexuality and Disability, 25, 111-123. https://doi.org/10.1007/ s11195-007-9045-9

Agmon, M., Sa'ar, A., \& Araten-Bergman, T. (2016). The person in the disabled body: a perspective on culture and personhood from the margins. International Journal for Equity in Health, 15, 147. https://dx.doi.org/10.1186\%2Fs12939-016-0437-2

Bloom, T. E., Mosher, W., Alhusen, J., Lantos, H., \& Hughes, R. B. (2017). Fertility desires and intentions among U.S. women by disability status: Findings from the 2011-2013 national survey of family growth. Maternal and Child Health Journal, 21(8), 1606-1615. https://doi.org/10.1007/ s10995-016-2250-3

Brito, T. D. Q., Oliveira, A. R., \& Eulalio, M. C. (2015). Deficiência física e envelhecimento: estudo das representaçôes sociais de idosos sob reabilitação fisioterápica. Avances en Psicología Latinoamericana, 33(1), 121-133. https://doi.org/10.12804/apl33.01.2015.09

Camargo, B. V., \& Justo, A. M. (2013). IRAMUTEQ: um software gratuito para análise de dados textuais. Temas em Psicologia, 21(2), 513-518. http://dx.doi.org/10.9788/TP2013.2-16

Camargo, B. V., Justo, A. M., \& Jodelet, D. (2010). Normas, Representaçóes Sociais e Práticas Corporais. Interamerican Journal of Psychology, 44(3), 449-457.

Camargo, B. V., Goetz, E. R., Bousfield, A. B. S., \& Justo, A. M. (2011). Representaçóes sociais do corpo: estética e saúde. Temas em Psicologia, 19(1), 257-268.

Chappell, P. (2014). How Zulu-speaking youth with physical and visual disabilities understand love and relationships in constructing their sexual identities. Culture, Health e Sexuality, 16(9), 1156-1168. https://doi.org/10.1080/13691058.2014.933878 
Costa, W. A., \& Almeida, A. M. O. (1999). Teoria das representações sociais: uma abordagem alternativa para se compreender o comportamento cotidiano dos indivíduos e dos grupos sociais. Revista de Educação Pública, 7(13), 173-187.

Damas, M. A., Pérez, Z. C., Reyes, N. M., \& López, A. B. (2015). Sexualidad y discapacidad: enfrentando estereotipos desde el documental audiovisual. Revista Cubana de Información en Ciencias de la Salud, 26(3), 273-279.

Dantas, T. C., Silva, J. S. S., \& Carvalho, M. E. P. (2014). Entrelace entre gênero, sexualidade e deficiência: uma história feminina de rupturas e empoderamento. Revista Brasileira de Educação Especial, 20(4), 555-568. https://doi.org/10.1590/S1413-65382014000400007

Decreto no 6.949, de 25 de agosto de 2009. Promulga a Convenção Internacional sobre os Direitos das Pessoas com Deficiência e seu Protocolo Facultativo. http://www.planalto.gov.br/ccivil_03/_ ato2007-2010/2009/decreto/d6949.htm

Diniz, D. (2007). O que é deficiência. Brasiliense.

Gartrell, A., Baesel, K., \& Becker, C. (2017). "We do not dare to love": Women with disabilities' sexual and reproductive health and rights in rural Cambodia. Reproductive Health Matters, 25, 31-42. https://doi.org/10.1080/09688080.2017.1332447

Goetz, E. R., Camargo, B. V., Bertoldo, R. B., \& Justo, A. M. (2008). Representação social do corpo na mídia impressa. Psicologia e Sociedade, 20(2), 226-223. https://doi.org/10.1590/S010271822008000200010

Goldenberg, M., \& Ramos, M. S. (2007). A civilização das formas: O corpo como valor. In M. Goldenberg (Org.), Nu e vestido: dez antropólogos revelam a cultura do corpo carioca (2a ed., pp. 19-40). Record.

Hunt, X., Swartz, L., Carew, M. T., Braathen, S. H., Chiwaula, M., \& Rohleder, P. (2017). Dating persons with physical disabilities: The perceptions of South Africans without disabilities. Culture, Health e Sexuality, 20(2), 141-155. https://doi.org/10.1080/13691058.2017.1334964

Jones, B. S., Duarte, B. T., Astorga, U. N., Pardo, M. M., \& Sepúlveda, P. R. (2015). Aproximación a la experiencia de cuerpo y sexualidad de un grupo de mujeres chilenas con discapacidad fisica congenita. Revista Chilena de Terapia Ocupacional, 15(1), 19-32. 10.5354/0719-5346.2015.37127

Justo, A. M., \& Camargo, B. V. (2013). Corpo e cogniçôes sociais. Liberabit, 19(1), 21-32.

Justo, J. S., \& Vasconcelos, M. S. (2009). Pensando a fotografia na pesquisa qualitativa em psicologia. Estudos e Pesquisas em Psicologia, 9(3), 760-774.

Maia, A. C. B. (2011). Inclusão e sexualidade: Na voz de pessoas com deficiência física. Juruá.

Maia, A. C. B., \& Ribeiro, P. R. M. (2010). Desfazendo mitos para minimizar o preconceito sobre a sexualidade de pessoas com deficiências. Revista Brasileira de Educação Especial, 16(2), 159-176. https://doi.org/10.1590/S1413-65382010000200002

Marini, I., Wang, X., Etzbach, C. A., \& Castillo, A. D. (2012). Ethnic, gender, and contact differences in intimacy attitudes toward wheelchair users. Rehabilitation Counseling Bulletin, 56(3), 135-145. https://doi.org/10.1177\%2F0034355212456605

McKenzie, J. A. (2013). Disabled people in rural South Africa talk about sexuality. Culture, Health $e$ Sexuality, 15(3), 372-386. https://doi.org/10.1080/13691058.2012.748936 
Morgado, F. F. R., Castro, M. R., Ferreira, M. E. C., Oliveira, A. J., Pereira, J. G., \& Santos, J. H. dos. (2017). Representaçóes Sociais sobre a Deficiência: Perspectivas de Alunos de Educação Física Escolar. Revista Brasileira de Educaçāo Especial, 23(2), 245-260. https://doi.org/10.1590/s141365382317000200007

Moscovici, S. (2010). Representaçôes sociais: investigaçôes em psicologia social. Vozes.

Neiva-Silva, L., \& Koller, S. H. (2002). O uso da fotografia na pesquisa em Psicologia. Estudos de Psicologia, 7(2), 237-250. https://doi.org/10.1590/S1413-294X2002000200005

Passos, M. D., Gugelmin, S. A., Castro, I. R. R., \& Carvalho, M. C. V. S. (2013). Representaçóes sociais do corpo: um estudo com adolescentes do Município do Rio de Janeiro, Brasil. Cadernos de Saúde Pública, 29(12), 2383-2393. https://doi.org/10.1590/0102-311X00027513

Pereira, O., Monteiro, I., \& Pereira, A. L. (2011). A visibilidade da deficiência: Uma revisão sobre as representaçóes sociais das pessoas com deficiência e atletas paralímpicos nos media impressos. Sociologia, Revista da Faculdade de Letras da Universidade do Porto, 22, 199-217.

Pérez, M. P. C. (2015). Acceso a derechos sexuales y reproductivos de las mujeres con discapacidad: El papel de las y los prestadores de servicios. La ventana. Revista de Estudios de Género, 5(42), 7-45.

Resolução $n^{\circ}$ 510, de 7 de abril de 2016. Dispóe sobre as normas aplicáveis a pesquisas em Ciências Humanas e Sociais. https://bvsms.saude.gov.br/bvs/saudelegis/cns/2016/res0510_07_04_2016. html

Soares, A. H. R., Moreira, M. C. N., \& Monteiro, L. M. C. (2008). Jovens portadores de deficiência: Sexualidade e estigma. Ciência e Saúde Coletiva, 13(1), 185-194. https://doi.org/10.1590/S141381232008000100023

Starke, M., Rosqvist, H. B., \& Kuosmanen, J. (2016). Eternal children? Professionals' constructions of women with an intellectual disability who are victims of sexual crime. Sexuality and Disability, 34 , 315-328. https://doi.org/10.1007/s11195-016-9441-0

Tanabe, M., Nagujjah, Y., Rimal, N., Bukania, F., \& Krause, S. (2015). Intersecting sexual and reproductive health and disability in humanitarian settings: Risks, Needs, and capacities of refugees with disabilities in Kenya, Nepal, and Uganda. Sexuality and Disability, 33(4), 411-427. https:// doi.org/10.1007/s11195-015-9419-3

Triani, F. S., Mendonça, I. F., Costa, T. G., \& Novikoff, C. (2015). O corpo e suas representações sociais no discurso científico. Educación Física y Deportes, 20(209). https://www.efdeportes.com/ efd209/o-corpo-e-suas-representacoes-sociais-no-discurso-cientifico.htm

Vasconcelos, J. L. L., Lima, T. M. S., \& Oliveira, M. R. H. S. (2017). Reprodução humana assistida: uma abordagem a luz dos direitos humanos fundamentais. In R. C. Pereira (Coord.), Direito das familias e sucessóes: concurso de artigos. (pp. 265-279). ${ }^{5}$ IBDFAM.

Recebido em: 25/09/2020

Reformulado em: 11/02/2021

Aprovado em: 27/02/2021 